\title{
The atmosphere of a street: Experimental fieldwork on urban ambiances
}

\author{
Andreas Wesener, ${ }^{1, *}$ \\ ${ }^{1}$ Lincoln University, Faculty of Environment, Society and Design, School of Landscape Architecture, \\ PO Box 85084, Lincoln 7647, Canterbury, New Zealand
}

\begin{abstract}
The paper discusses phenomenological fieldwork carried out by third- and fourth-year students enrolled in the Bachelor of Landscape Architecture programme at the School of Landscape Architecture at Lincoln University. It focuses on students' sensory experiences while surveying a lively inner-urban street in Wellington, New Zealand, and discusses related (objective) circumstances, sensations and interpretations. Students were asked to describe their experiences while moving through the street and to record them in a field book in the form of notes and sketches. The goal of the paper is to capture, analyse and discuss students' individual experiences of different atmospheric facets of an urban streetscape. Preliminary findings are presented and discussed.
\end{abstract}

\section{Introduction}

Atmospheres or ambiances are phenomena that are emotionally-corporally 'felt' rather than cognitively 'understood' [1-4]. They have been conceptualised as "Halb-Dinge" (half-things) [5, 6], "immaterielle Sonderdinge" (immaterial exceptional things) [7], and mediations between subject and object [8] that may not be directly perceived, however, may affect a person's bodily and/or metal condition. According to Schmitz's [9] concept of "affektives Betroffensein" (affective involvement), atmospheres may significantly influence people's moods when spatially accessed or 'entered'.

In an urban context, atmospheres are noticeable but transitory qualities that may capture people's senses. Their particular spatial position is not defined; however, "[ $\mathrm{t}]$ hey seem to fill the space hazily with an emotional tone" ${ }^{\dagger}[10]$. Although not directly attached to material objects, atmospheres rarely do exist without physical space and have accordingly been considered as a powerful "link between space and sensitivity" [11]. While atmospheres cannot be measured directly, particular spatial attributes related to atmospheres such as narrowness, width, depth and surface have been identified [12]. Böhme suggests that objects are not only determined by their physical characteristics, but also by the way they 'come out'

\footnotetext{
* Corresponding author: andreas.wesener@lincoln.ac.nz

${ }^{\dagger}$ Original German phrases in this paper have been translated into English by the author.
} 
and provide "weight and orientation" to the surrounding space. He concludes that it is possible to conceptualise atmospheres as spaces '"tinted' by the presence of objects, people, or environmental constellations" [10].

Architecture can be experienced visually but also through "tactile reception" [13], e.g. the way the built environment is entered, walked through, and used. Experiencing architecture and the built environment may therefore be a matter of 'feeling' as much as 'seeing' [14]. While the urban built environment supports the production of atmospheres [15], urban landscapes are experienced as holistic combinations of sensory, habitual, and socio-cultural phenomena including class- or milieu-orientated self-representations [1]. Experiencing and remembering vital qualities of a place [cf. 15] might be a matter of holistic atmospheres rather than singular phenomena:

"Cities have atmospheres. They are fleeting like the scent of a rose. As this is not part of the blossom, the atmosphere is not attached to the physical space of the city. And yet, without the materiality of the blossom there is not its scent and without the materiality of the city not its atmosphere." [1]

The study focuses on the sensory experience of streetscapes and related atmospheres. Urban streets are public open spaces that allow people to move around freely and experience the city. They are places where urban life rolls by [16] offering particular sensory experiences that only streets can provide. However, such experiences can differ significantly depending on the geographical, historical and socio-cultural context. The paper analyses and discusses the phenomenological fieldwork of third- and fourth-year undergraduate students enrolled in the Bachelor of Landscape Architecture (BLA) programme at the School of Landscape Architecture (SOLA) at Lincoln University. The students were asked to describe the atmosphere(s) of a section of Cuba Street in central Wellington, the capital of New Zealand, while moving through the space. Students were asked to refer to physical characteristics, smells, sounds, etc., in relation to their own experience and to describe any change of atmosphere while continuing their walk. The paper follows the theoretical and methodological framework used in a similar study [16] carried out with geography students in the historic 'Drosselgasse' in Rüdesheim, Germany. It presents and discusses preliminary findings.

\section{Theoretical and methodological framework}

Following Hasse's Drosselgasse study [16], the paper combines the philosophical-theoretical framework of Hermann Schmitz's [17] Neue Phänomenologie (New Phenomenology) with empirical qualitative social research methods. Schmitz regards the study of human subjectivity and related feelings and bodily experiences as a relevant epistemological complement to the rationalistic-reductive forms of scientific inquiry. At the centre of his investigation are phenomena that show or manifest themselves and their corresponding effect or impact on individual human beings that experience them. While clearly linked to the five senses of human perception, phenomenological experience is symptomatically a "diffuse unity between subject and object" [16]; a constructive process between subjective feeling and interpretative cognition that includes associative and 'learned' socio-cultural norms, constructs, symbols and interpretative patterns. Experiences can holistically combine sensations and interpretations to an extent that interpretations are experienced as feelings [16].

In our study, twenty third- and fourth-year BLA students were asked to describe the atmosphere(s) of a part of Cuba Street in central Wellington (Figure 1) while moving through 
the space. The students were on a one-week field trip in April 2017. Their programme included several site visits, a design charette with students from other New Zealand universities, and attending a conference.

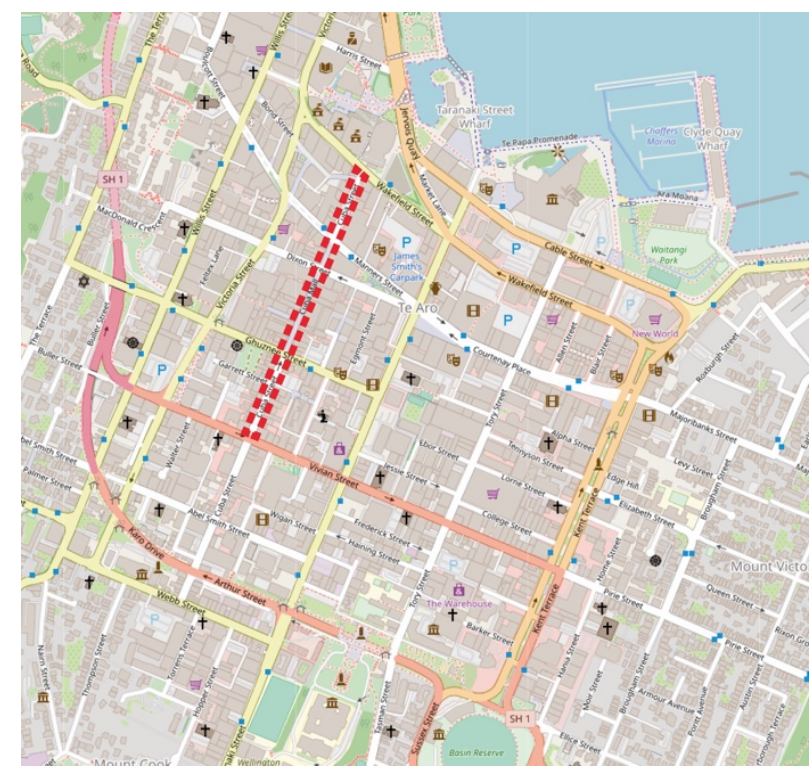

Fig. 1. Wellington city centre (not to scale); case study area highlighted. Contains information from OpenStreetMap (http://openstreetmap.org/copyright; http://openstreetmap.org), which is made available under the Open Database License (ODbL).

Students were asked to refer to the visual, physical-material characteristics, smells, sounds, etc. of the streetscape in relation to their own experience that may include interpretations and feelings including different moods, fears, joys, excitements, etc. They were asked not to share and discuss their experiences with other students during the study. The field work took about two hours to be completed. Students had to submit up to two A4 pages including detailed descriptions and sketches to help illustrate their experiences. From 20 submitted descriptions, three were excluded as they contained only irrelevant information.

Descriptions of holistic 'situations' combine objective and subjective circumstances. Following Hasse's approach [16], however using a slightly revised and simplified category system, students' holistic descriptions were systematically coded through deductive qualitative content analysis. Three main deductive categories were used to systematise students' heterogenous descriptions of perceptions, feelings and interpretations: (1) objective circumstances (objektive Sachverhalte); (2) sensations (sinnliche und leibliche Eindrücke); and (3) interpretations (Deutungen). The three main categories were subdivided in first level sub-codes, and - if necessary - second level sub-codes.

Following Schmitz [18], objective circumstances are based on sensory perceptions (mainly visual; auditory; olfactory; tactile). However, they are not necessarily factually 'true' 
or indisputable. Their main characteristic is that they are communicable - principally by everyone. Objective circumstances are core elements of "inter-subjectively similar perceptions" [16]. They include physical-material characteristics, such as buildings, shops, architectural details, plants and vegetation, construction materials; visual impressions, such as colours, light; people; sounds including music and smells, e.g. from food outlets, cafes and bars.

In contrast, subjective circumstances can only be communicated by one person [18]. They are based on individual experiences and feelings and related to a person's subjective or affective involvement in a situation. Although often related to objective circumstances, subjective circumstances can be clearly distinguished [16]. The paper defines sensations as situative sensory and bodily experiences that are emotionally-corporally 'felt'. For instance, a narrow spatial situation (objective circumstance) can be experienced as 'crammed' and 'uninviting' or 'enticing' and 'welcoming'. Finally, subjective involvement can also be expressed in the form of interpretations. These are descriptions of 'learned' symbolic or socio-cultural relations including subjective programmes, problems or wishes that are cognitively 'understood' [16]. For example, a shop could be experienced as 'unique' as well as 'commercialised'.

Hasse [16] recognises a relationship between sensations and interpretations. Feelings and bodily experiences can be expressed through cultural symbols and triggered by them. Both emotionally-corporally experiences (feeling) and interpretative reflection (thinking) are part of a person's holistic assessment of a situation. Objective circumstances, particularly physical-material characteristics, have a relevant, however, indirect influence on the atmosphere of a place. While an atmosphere is an amalgamation of objective and subjective circumstances, it can only be 'accessed' through situative experience, here operationalised in the form of sensations and interpretations (cf. Figure 9). From a methodological perspective, an unequivocal distinction between sensations and interpretations is not always possible. In consequence, the systematisation and transferability of empirical categories related to atmospheres remains difficult [16].

Hasse [16] utilised a fourth category called objective programmes. Based on Schmitz's Programme [18], an objective programme is an interpretative-symbolic category that includes formalised or institutionalised socio-cultural constructs such as norms and rules. Objective programmes and (subjective) interpretations are linked; making an explicit distinction between them can be ambiguous, particularly if the empirical data is based on written descriptions alone. Therefore, it was decided to exclude this category in this study.

\section{The case study: Cuba Street, Wellington}

Cuba Street is a prominent urban street in Wellington's inner city. It evolved from a former red-light district into a busy, partly pedestrianised shopping street including numerous cafes, food outlets, and boutique shops. Since 1995, it is a registered historic area under the Historic Places Act 1993 due to relevant historic buildings, facades, and architectural details from the nineteenth and early twentieth century. Various key destinations including the Wellington Arts Centre and Victoria University's Faculty of Architecture and Design are nearby. For this study, Cuba Street between Vivian Street to the south and Wakefield Street to the north was used as a case study for phenomenological inquiry. 


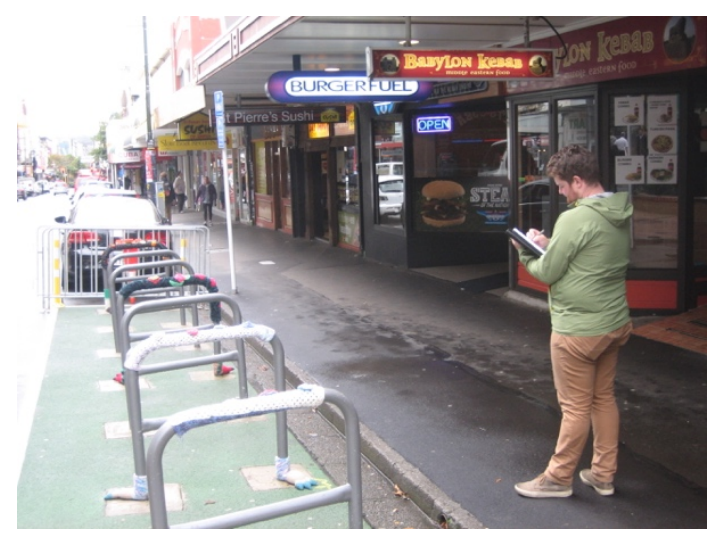

Fig. 2. Southern part of Cuba Street between Vivian and Ghuznee Street with third-year student making field notes

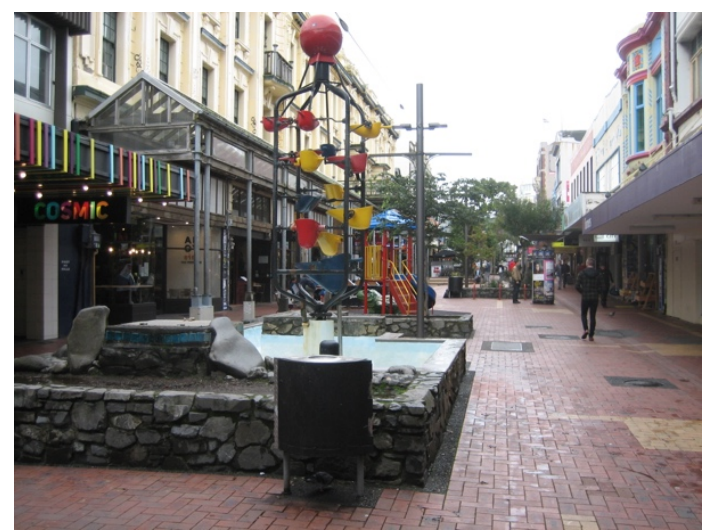

Fig. 3. Pedestrianised mall with 'Bucket Fountain'

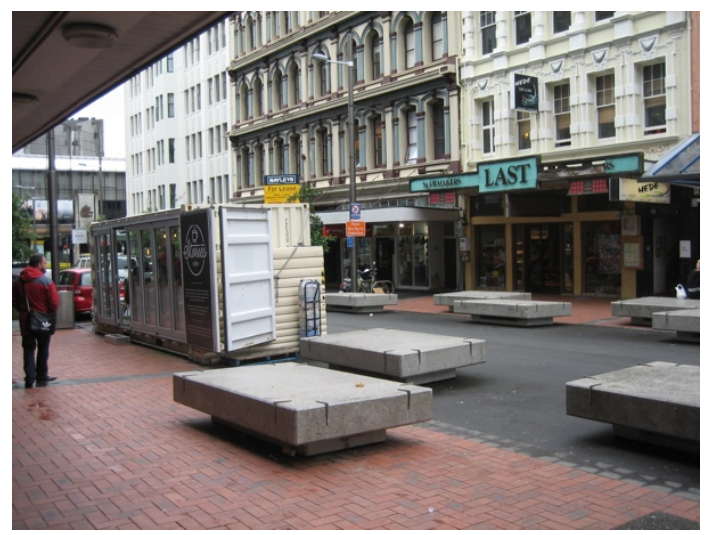

Fig. 4. Shared space with food container between Manners and Wakefield Street

The southern part between Vivian and Ghuznee Street (Figure 2) is a regular (vehicular) one-way street featuring predominantly small-scale street-lining buildings with overhanging canopy structures that cover the pavement. The street is dominated by food outlets on the 
ground floor. The middle part between Ghuznee and Manners Street is a pedestrianised mall. It features coloured pavement, planters, trees and sculptures including the iconic 1969 'Bucket Fountain' (Figure 3). The northern end between Manners and Wakefield Street is a one-way street with shared space design characteristics (Figure 4). It includes a mix of larger historical and mid- to late twentieth century buildings.

\section{Preliminary findings}

\subsection{The changing atmosphere of Cuba Street}

Students noticed explicit and subtle changes of the urban atmosphere while walking through Cuba Street from south to north. The upper (southern) part evoked descriptions of car traffic, narrow roads, and the canopy above the pavement that prevented to see the sky and created a sort of tunnel effect (Figure 5). The place was described as full of people and food smells were noted. Related sensations were often negative; the place felt busy but uninviting, noisy, tight, crammed, dense, messy and enclosed. However, the street also "pulls you in" (student 11) awaking feelings of curiosity. Cognitive interpretations included 'diverse' and 'cultural' - particular in relation to people - and vehicle-dominated. Some students experienced an amalgamation of impressions including objective circumstances and related - sometimes contradicting - sensations and interpretations. For example, student 16 noted with regard to the upper part of Cuba Street: "Enclosure; food smells amazing; [...] a sense of belonging, even though it's a strange environment".

The atmospheric accounts changed after the crossing of Ghuznee Street with the beginning of the pedestrian mall. A feeling of openness and space was expressed; to the extent that it was felt that a weight had been lifted: "[...] then after feel[ing] enclosed, I've been released from the pressure because we suddenly enter an open space" (student 14). Students' descriptions became generally richer and included street furniture, architectural details, trees and urban green, sculptures and playground elements. The presence of people that gather in social places (cafes, outdoor seating) and the openness and permeability between inside and outside areas (Figure 6), buildings and open space ('active frontages', 'open shop fronts', 'lots of windows') were frequently noted including positive atmospheric descriptions such as 'welcoming', 'comfortable' and 'inviting'.

Sensations related to physical characteristics and people made part of amalgamated atmospheric accounts: "Changes after the first street. Bustling, colourful, unique, peaceful, messy - but in a good way" (student 8). Trees, gardens and greenery were generally appreciated and related to a 'calming feeling'. The absence of cars and the larger, coloured paving were related to feelings of safety; the absence of traffic noises was described as being pleasant. A general change of environmental sounds was noted: "less cars, more chatter, music" (student 7) and "pigeons, talking, footsteps, light sound, jackets rustling" (student 8). 


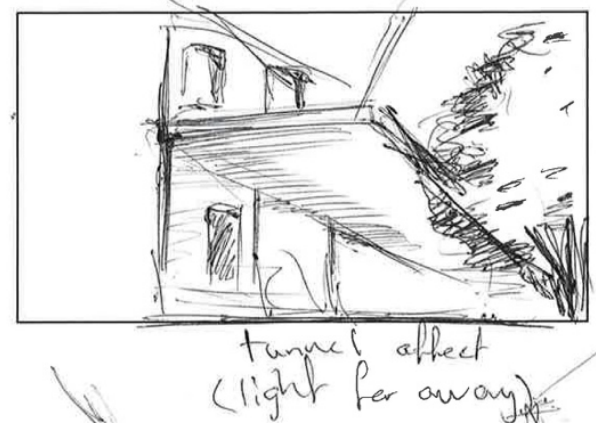

Fig. 5. Southern part of Cuba Street - 'tunnel effect' (field sketch; student 16)

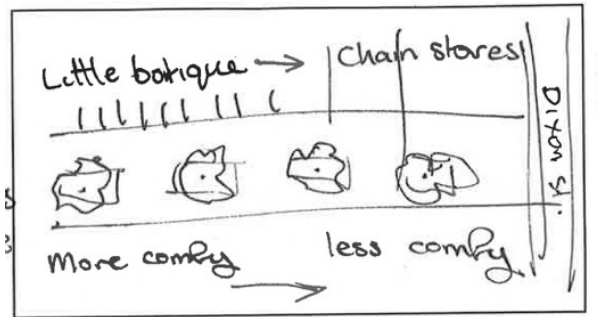

Fig. 7. Small boutique shops vs. big chain stores (field sketch; student 1)

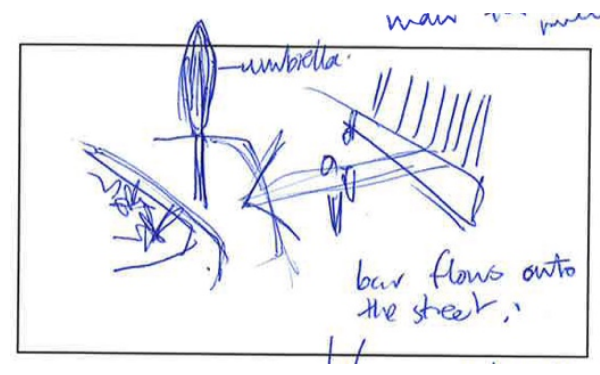

Fig. 6. Inside/outside relationship; socialising area (field sketch; student 11)

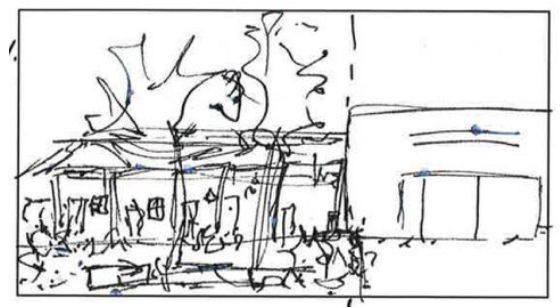

Fig. 8. Small boutique shops vs. big chain stores (field sketch; student 8)

However, students also noticed an atmospheric change within Cuba Street mall when smaller 'boutique' shops made way for larger 'commercial' stores: "Boutique stores are more comfortable to walk past with higher variety of people; once the larger stores start, you feel like you have to be doing something/going somewhere" (Figure 7). Another student noted: "Contrast between small boutique stores and large commercial stores - they ruin the homely feel!" (Figure 8). The same student observed a "divide between unique = inviting to bright and commercial", exemplifying a "diffuse unity" [16] between objective circumstances, sensations and interpretations. Students' activities were occasionally noticed by passers-by who inquired about what students were doing. Such interactions with strangers were experienced as friendly, safe, and welcoming.

At the northern end of Cuba Street, atmospheric accounts changed again. The reappearance of a vehicular road and more cars was perceived as "less inviting" and "out of place". The (larger) buildings were experienced as "overpowering, rugged, unpolished, starch, finished and clean" (student 7). Some experienced the area as "pedestrian-focused" (student 11) and still pleasant but more commercial and "losing its touch" (student 9). The street was also identified as a mixed-use area that "draws people in" (student 5); public transport and temporary uses of space were noticed. Sounds and smells did not play a significant experiential role in this section of Cuba Street.

\subsection{Atmospheric components}

Students collected almost 200 descriptions of objective circumstances in their field notes and sketches. These were categorised and subdivided into eight sub-codes including (visual) physical-material characteristics, people (moving around \& doing things), music and other sounds, silence/quietness, food and other smells, weather/microclimate, tactile experiences 
and amalgamated impressions (e.g. "open noisy traffic"). Visual physical characteristics were most frequently mentioned as a sub-code within the objective circumstances category, followed by people. Sounds and smells were less frequently mentioned in students' accounts.

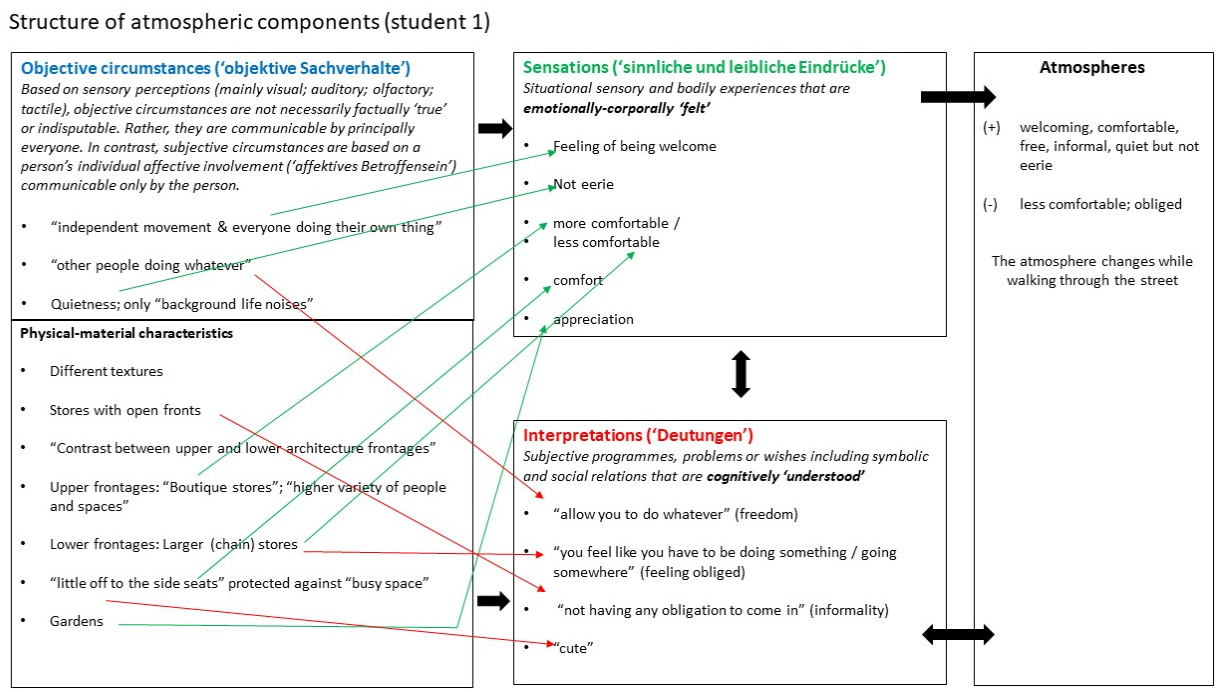

Fig. 9. Structure of atmospheric components (exemplary; based on descriptions of student 1)

Figure 9 depicts an exemplary structure of atmospheric components based on the field notes of student 1. It relates to Hasse's "Emergence of atmospheres" diagrams 4 and 5 [16]; however, without the objective programmes category (cf. section 2 in this paper). The diagram depicts the relationship between the three main categories of analysis (objective circumstances, sensations and interpretations). It shows the indirect influence of objective circumstances on atmospheres; (visual) physical-material characteristics are depicted separately. The green arrows depict the relationships between objective circumstances and sensations; the red arrows show relations between objective circumstances and interpretations. The atmosphere field in the diagram includes positive (+) and (-) negative accounts of atmospheres derived from the sensations and interpretations categories. The relationship between interpretations and atmospheres is potentially leading in both directions; atmospheres may influence interpretations and vice-versa.

Students provided almost 70 accounts of sensations. These were subdivided into positive, negative and neutral sensations. In addition, there were some accounts of amalgamated or 'chain' sensations that combined different sensations that apparently occurred together and sometimes added up to a particular attitude towards a place: "Feel increasing humidity; cooler; feeling strange; doesn't feel lively; no particular place to go; I'd rather avoid this place" (student 14). The total number of interpretations in students' descriptions was similar to the number of sensations. They were subdivided in 10 sub-codes. The majority of interpretations were of positive nature; however often unspecified such as 'cute', 'beautiful', 'nice', 'good', 'hip', 'interesting', 'great', or 'gorgeous'. Frequently described, specified positive interpretations were 'unique' (e.g. with regard to small boutique stores and different people), 'active' and 'lively' (e.g. with regard to people and their activities, but also visual stimuli such as colours), and 'not boring' (e.g. with regard to spatial design details and visual stimuli such as diverse colours). Unspecified negative expressions included 'ugly' and 'tacky' (e.g. with regard to street furniture and buildings). A frequent specified negative 
impressions was 'commercial', e.g. with regard to (large) shops and the streetscape, particularly towards the lower end of Cuba Street. Neutral interpretations included 'hidden', 'permeable', 'cultural', and 'diverse'.

\subsection{The built environment}

Students' disciplinary backgrounds (landscape architecture and design) raise questions about the influence of education and pre-existing knowledge on the experience of urban atmospheres. In order to analyse this influence, the objective circumstances' visual physicalmaterial sub-code was further sub-divided to examine elements related to architecture, landscape architecture and spatial design including spatial change. Perhaps not surprisingly, 91 out of 126 descriptions of visual physical-material objective circumstances related to architecture, landscape elements, and spatial characteristics including change. The occurrence of 'disciplinary jargon' (e.g. active frontages; mixed-use; temporary uses; density) was, however, limited.

It seems relevant that students, although explicitly asked to focus on the entire range of sensory experiences and related atmospheres, predominantly communicated visual experiences related to their professional knowledge that is part of landscape architecture and urban design education. Descriptions were influenced by (learned) inventory/analysis techniques and focused predominantly on material-physical characteristics. However, even though students' spatial design background may have caused a sort of sensory imbalance, their accounts provide nevertheless a rich description of atmospheric components. Expressed sensations and interpretations, related to the spatial contrast between narrow/enclosed and wide/open space and between a fine and coarse urban grain, as much as experiences around active frontages and social open space, pedestrian-focused streets and green urban infrastructure provide relevant information about the 'feel' of the street. 


\section{Some preliminary conclusions}

Atmospheres are influenced by objective and subjective components and can be empirically examined through phenomenological analysis. In this paper, atmospheric analysis has been operationalised in the form of objective circumstances, sensations and interpretations following Hermann Schmitz's Neue Phänomenologie framework [17] and Hasse's influential pilot study in Rüdesheim [16]. The preliminary findings of the study show that 'lived urban space' can provide holistic and dynamic experiences including changing urban atmospheres that unfold while moving through the space. Students' descriptions provide a diverse account of changing atmospheres based on their feelings, bodily experiences and cognitive interpretations while walking through different sections of Cuba Street.

While students' descriptions showed a sensory preference for physical-material and spatial objective circumstances - likely based on their disciplinary background - some accounts revealed complex experiential amalgamations that included objective and subjective components. The combined experience of particular spatial configurations, people and sounds such as the combination of a narrow and crowded street, overhead structures that limit views of the sky, cars and noisy traffic created a specific atmosphere, in this case connected to negative feelings of enclosure that, however, disappeared as soon as the space changed again. The study confirms that urban design and architecture have an important influence on atmospheres. However, urban atmospheres cannot be 'designed' in isolation. They depend on the people who contribute to them: "The lived life turns spaces into 'lived places' and historic places" [16].

As with all single case studies, the transferability of the findings in this paper is limited. However, the study contributes an antipodean perspective to an otherwise predominantly Eurocentric discussion. It strengthens the argument that qualitative empirical research with regard to experiential aspects of urban space remains highly relevant for the spatial disciplines including urban design, planning and (landscape) architecture. Urban design research has an increasing focus on public open space as a place for community interaction and social exchange [19-22]. Popular concepts and international movements such as 'place making' have evolved in reaction to a perceived decline of experiential qualities and alienated 'non-places' [23], characterized by a lack of history, identity, social relations and, eventually, authenticity [24-26]. Urban ambiances may be fleeting; however, they are relevant constituents of places. It would be rather senseless to ponder on 'a sense of place' without considering its atmospheric qualities. 


\section{References}

1. J. Hasse, Die alte Stadt. 35, 2, 103-116 (2008)

2. R. Kazig, Die alte Stadt. 35, 2, 147-160 (2008)

3. J.-P. Thibaud, En quête d'ambiances. Éprouver la ville en passant (MētisPresses, Genève, 2015)

4. T. Griffero The atmospheric "skin" of the city. Ambiances - International Journal of Sensory Environment, Architecture and Urban Space, 2013.

5. G. Böhme, Aisthetik. Vorlesungen über Ästhetik als allgemeine Wahrnehmungslehre (Wilhelm Fink Verlag, Munich, 2001)

6. H. Schmitz, Der Leib, der Raum und die Gefühle (Aisthesis Verlag, Bielefeld, 2007)

7. J. Hasse, Zum Verhältnis von Stadt und Atmosphäre. Wo sind die Räume der Urbanität?, in Subjektivität in der Stadtforschung (Institut für Didaktik der Geographie, Frankfurt am Main, 19-40, 2002)

8. R. Kazig, Atmosphären - Konzept für einen nicht repräsentationellen Zugang zum Raum, in Kulturelle Geographien (Transcript-Verlag, Bielefeld, 167-187, 2007)

9. H. Schmitz, Leib und Gefühl. Materialien zu einer philosophischen Therapeutik (Junfermann, Paderborn, 1992)

10. G. Böhme, Atmosphäre (Suhrkamp, Frankfurt/Main, 1995)

11. G. Böhme, Oase - Journal for Architecture. 91, 21-32 (2013)

12. H. Schmitz, System der Philosophie. Dritter Band: Der Raum. Zweiter Teil: Der Gefühlsraum (Bouvier Verlag, Bonn, 2005)

13. W. Benjamin, The Work of Art in the Age of Mechanical Reproduction (Penguin, London, 2008 [1936])

14. G. Böhme, Architektur und Atmosphäre (Fink, Paderborn, 2006)

15. S. Runkel and A. Wesener, "Rencontre sur les lieux": memory construction in urban ambiances, in Ambiances in action - ambiances en actes(s). Proceedings of the 2 nd International Congress on Ambiances (Ambiances International Network, Montreal, 121-126, 2012)

16. J. Hasse, Die Atmosphäre einer Straße. Die Drosselgasse in Rüdesheim am Rhein, in Subjektivität in der Stadtforschung (Institut für Didaktik der Geographie, Frankfurt am Main, 61-113, 2002)

17. H. Schmitz, Neue Phänomenologie (Bouvier, Bonn, 1980)

18. H. Schmitz, Neue Grundlagen der Erkenntnistheorie (Bouvier, Bonn, 1994)

19. J. Gehl, Cities for People (Island Press, Washington D.C., 2010)

20. J. M. Jacobs, The Death and Life of Great American Cities (Random House, New York, 1961)

21. W. H. Whyte, The Social Life of Small Urban Spaces (Conservation Foundation, Washington D.C., 1980)

22. M. Carmona and F. M. Wunderlich, Capital Spaces: The multiple complex public spaces of a global city (Routledge, Oxon, 2012)

23. M. Augé, Non-Places: Introduction to an Anthropology of Supermodernity (Verso, London, 1995)

24. A. Wesener, The Good, the Bad, the Authentic: An evaluation of concepts, experiences, and considered values of authenticity of place in the context of the post-industrial city (Königshausen \& Neumann, Würzburg, 2014)

25. A. Wesener, Journal of Urban Design. 21, 1, 67-83 (2016)

26. A. Wesener, International Journal of Heritage Studies. 23, 2, 141-155 (2017) 